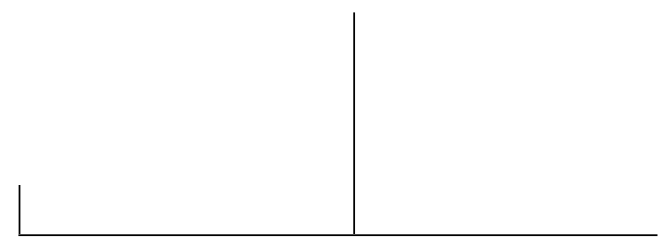

Rev. Latinoam. Psicopat. Fund., São Paulo, 16(2), 218-231, jun. 2013

\title{
Mulher perversa?*
}

Rita Maria Manso de Barros

Ligia Gama e Silva Furtado de Mendonça

Este artigo propõe discutir a existência de mulheres estruturalmente perversas a partir da teoria psicanalítica por meio das contribuições de Freud e Lacan. Inicialmente, ao estudar a perversão, há a dificuldade de isolá-la como uma estrutura específica distinguindo-a da psicose e da neurose devido à manifestação polimorfa-perversa da sexualidade humana. Entretanto, uma das questões mais discutidas é se há mulher na estrutura perversa, ou se ela é restrita apenas aos homens.

Palavras-chave: Perversão, psicanálise, mulher, feminino

*Artigo baseado na Dissertação de Mestrado intitulada "Há mulher na estrutura perversa?", de Ligia Gama e Silva Furtado de Mendonça e orientada pela dra. Rita Maria Manso de Barros, defendida em 2012 na Universidade do Estado do Rio de Janeiro (UERJ). 
Este artigo parte de uma pergunta, uma inquietação. Expliquemo-la: na psicanálise, especialmente na vertente lacaniana, sustenta-se que não poderia haver mulheres na estrutura perversa uma vez que elas não têm como desmentir (Verleugnung) a castração. Mas por qual motivo seria vetada às mulheres a estrutura perversa?

Em um de seus mais interessantes artigos sobre a posição feminina, Freud (1931/2006) afirma que a percepção da diferença sexual difere entre os sexos, sobretudo porque a linguagem, o grande $\mathrm{Ou}-$ tro, já os fala no masculino ou no feminino. Ele então estabelece que no caso da menina, este é o momento em que ela vê, sabe que não tem, que nunca teve, e que jamais poderá vir a ter o pênis/falo, o que impossibilitaria a ela o uso do mecanismo característico da perversão. Este encontro com o Real marcaria as diferenças sexuais entre o masculino e o feminino: o menino vê algo que falta, acredita ter o pênis/ falo e teme perdê-lo. Esta diferença de posição, quando o sujeito já está identificado a um sexo (sou menino ou sou menina), determina a forma como cada um vivenciará o momento, sempre traumático, de se deparar com o limite, com a perda do paraíso narcísico da igualdade. É a linguagem, que habita o corpo, a responsável pelo caminho da identificação com um ou outro sexo. A partir daí, no pensamento psicanalítico, o menino dissolveria o complexo de Édipo, dissolução que, como em qualquer soluto, como açúcar na água, deixaria, no melhor dos casos, um adoçamento na relação com aqueles que são despojados de tal atributo: as mulheres, a começar pela sua própria mãe, já não mais fálica. Nas meninas, de forma diversa, a percepção da diferença sexual as afasta de suas mães, antes fálicas, poderosas ou completas, em direção àquele que detém o mesmo poder que antes atribuíam às mães: o pai.

A crença no falo, como vemos, é comum a ambos os sexos: um acredita ter, a outra sabe que jamais o terá e começa a tentar ser o falo para o outro que supõe tê-lo. Esta última posição impossibilitaria à menina o recurso do mecanismo do desmentido, base da entrada na estrutura perversa, restrita apenas aos meninos: ele viu, sabe agora que a mãe não tem, experimenta intensa angústia, e não quer 
mais saber disso. Procurará sempre algum objeto que recubra a falta fálica no outro (seja mulher ou homem): um fetiche, no mais suave dos casos, até posições anteriores ao momento da experiência traumática: canibalismo, sadismo, masoquismo, voyeurismo, exibicionismo - nomenclatura fartamente usada por Freud ao descrever a sexualidade infantil perversa-polimorfa. A menina não teria este recurso: ela não tem como fugir ao encontro com o real da castração, só lhe restando o recalque (Verneinung) ou a foraclusão (Verwerfung) da falta fálica. Pode ser louca, histérica ou obsessiva, mas nunca perversa!

Então, neste artigo compartilharemos com os leitores, já íntimos da questão, nossas indagações sobre a existência ou não de mulheres estruturalmente perversas, já que temos tantas notícias de mulheres tão cruéis quanto homens, embora crueldade não seja sinônimo de perversão.

\section{De Freud a Lacan... e outros autores}

Compreende-se que, desde Freud, a impossibilidade de haver mulher na estrutura perversa era um fato demonstrado clinicamente. Lacan não destoa dele.

Freud, quando relatava casos de perversões, como podemos observar em sua conferência intitulada "Sobre a gênese do fetichismo" (1909/1992) e nos textos "O problema econômico do masoquismo" (1924/2007) e "Fetichismo" (1927/ 2007), só se atinha a exemplos do sexo biológico masculino (exceto em 1909 quando incluía todas as mulheres na categoria de fetichistas de vestimentas). Contudo, os casos citados nestes textos não tratam de posicionamento feminino, até porque, se fosse uma questão de posicionamento, encontrar-se-iam mais facilmente relatos de mulheres - corpo biológico - perversas. Logo, percebemos o impasse que há ao relacionar perversão e mulher. Por que aqui a anatomia se torna tão relevante?

Tomemos o fetichismo primeiro, uma vez que supõe-se não haver mulher fetichista. Lacan (1956-1957/1995) afirma que “o fetichismo é excessivamente raro na mulher, no sentido próprio e individualizado em que ele se encarna num objeto que podemos considerar como respondendo, de uma maneira simbólica, ao falo como ausente" (p. 156-157), uma vez que, como sabemos, o objeto fetiche serve como obturador da angústia. Mais recentemente, Valas (1990, p. 114) reafirma à sua maneira a assertiva lacaniana ao pontuar que "[...] as grandes posições perversas são devolvidas ao homem, e não à mulher. A razão para isso seria a seguinte: a mulher não pode desmentir a castração, pois está marcada em seu próprio ser pelo seu selo". 


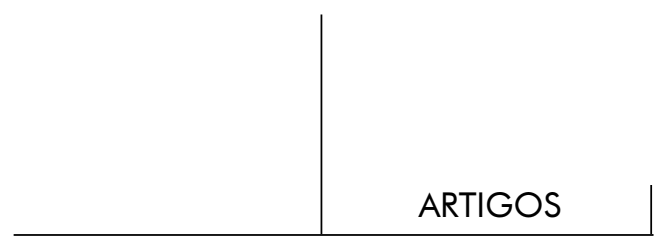

De maneira diversa pensa o psiquiatra e psicanalista estadunidense Robert Stoller, cujas pesquisas com transexuais publicadas em 1968 com o título Sex and gender serviram de fonte para Catherine Millot (1992) em sua tese de doutoramento. Ele atribui a identificação inicial como determinante da posição sexual, em vez da escolha objetal. Lembremo-nos que Freud (1921/2006, p. 117) afirma que "a identificação constitui a forma original de laço emocional com um objeto". Ele nada comenta sobre o sexo do bebê, o que nos faz entender que ambos, meninos e meninas, têm na identificação a forma de se ligar ao objeto antes mesmo que possam fazer uma "escolha" de definição sexual ou do objeto para onde dirigirão sua libido. Neste sentido, para Stoller, se a criança está inicialmente identificada à mãe, o caminho dos meninos para atingir a masculinidade é mais tortuoso do que o das meninas para alcançar a feminilidade: eles teriam de abandonar a identificação à mãe para identificarem-se ao pai e assim poder entrar no Édipo positivo. Isso explicaria porque alguns meninos iriam pelo caminho do transexualismo, idealizando o lugar da mulher como da Virgem Maria, solicitando a remoção do pênis. Ainda, para este autor, a primazia pertence ao seio (e não ao pênis) e a consequente capacidade de procriação da mulher. Isso significa que os meninos atribuem um falo à mulher para negar a superioridade - e não a inferioridade - dela. Segundo Ferraz (2004), só assim Stoller consegue compreender porque a perversão incidiria com maior frequência nos homens, já que, para ele, a formação da masculinidade é menos linear e simples do que o caso das mulheres. Seguindo a elaboração freudiana - onde a feminilidade é mais complexa de se atingir do que a masculinidade - por que haveria poucas mulheres perversas?

\section{Perversão-polimorfa e estrutura perversa}

Como pontuou Askofaré (2006), a perversão-polimorfa tem dois sentidos. Inicialmente é um momento da posição do sujeito: em função da falta da primazia do falo, a criança só dispõe das pulsões sexuais parciais como modos de acesso ao gozo. Assim sendo, a principal característica da perversão polimorfa é a de ser um regime de gozo. Mas Freud também se refere a ela como uma predisposição a todas as perversões, como um traço universal e original do ser humano. Logo, apesar de a predisposição perverso-polimorfa ter sido estabelecida a partir da observação de crianças, ela não é atrelada à idade e, sim, à força da pulsão. Nos "Três ensaios sobre a teoria da sexualidade" (1905/2006), Freud atenta que na experiência cotidiana, as transgressões perversas são um componente que raramente falta na vida sexual das pessoas sadias. Ainda, em circunstâncias 
favoráveis, essas pessoas podem substituir o alvo sexual 'normal' por alguma perversão.

A perversão como estrutura clínica só se constitui por meio de uma 'tomada de posição' frente à castração, também atuando como uma defesa; o sujeito perverso busca o não encontro com a castração, com o que falta. Não é à toa que Freud denomina de desmentido (Verleugnung) o mecanismo utilizado pelos perversos perante o horror da castração, onde a percepção da castração materna é negada. Esse processo, no entanto, não é raro na vida psíquica da criança, mas, se preservado, é o que retorna sob a forma da fantasia na mulher fálica. Diante do confronto com a castração, a criança empreende uma ação muito enérgica para sustentar essa renegação da percepção da realidade. E é a dominância da renegação na orientação da subjetivação que constitui o mecanismo que justifica a perversão como estrutura clínica.

Alberti (2005) afirma que Freud identificava em 1905 a perversão com a monotonia da satisfação de um desejo pela via do gozo fálico, utilizando apenas um único objeto de satisfação: o sujeito perverso se limita ao gozo de uma única e exclusiva maneira. Em 1927, ele pôde concluir que a perversão é a crença no falo materno, "o desmentido da castração, a recusa de reconhecer que falta alguma coisa ao Outro, por mais que no fundo o sujeito saiba perfeitamente que falta alguma coisa ao Outro (é somente o sujeito psicótico que não o reconhece, foracluindo essa falta)" (p. 27). Portanto, é a partir do simbólico que se pode fazer o diagnóstico diferencial estrutural por meio dos três modos de negação do Édipo - negação da castração do Outro - correspondentes às três estruturas clínicas. No caso da perversão, o que se nega é conservado no fetiche.

O que há de mais revelador e enriquecedor no texto "Fetichismo" (1927/ 2007) é que nele Freud esclarece o fetiche como um substituto do pênis da mulher, que carrega todo o interesse dirigido outrora ao seu predecessor, além de atuar como triunfo sobre a ameaça de castração e também como uma proteção contra a mesma. No entanto, esse substituto, cuja função é tamponar a falta e proteger o sujeito contra o horror da castração, não proporciona o esquecimento deste horror. Há um compromisso intermediário perante o conflito entre a percepção indesejada da realidade e a força de seu contradesejo de recusar (Verleugnung) a castração (continuando então a crer na mãe fálica); o eu se cinde permitindo reconhecer o perigo real e renunciar à satisfação pulsional ao mesmo tempo em que renega a realidade e busca a satisfação pulsional, como foi ressaltado em 1940[1938]/2007.

Se desde os "Três ensaios..." (1905) Freud já dava significativos passos em direção a uma diferenciação entre o polimorfismo das manifestações da sexualidade humana e a perversão como estrutura clínica, foi no já citado texto 


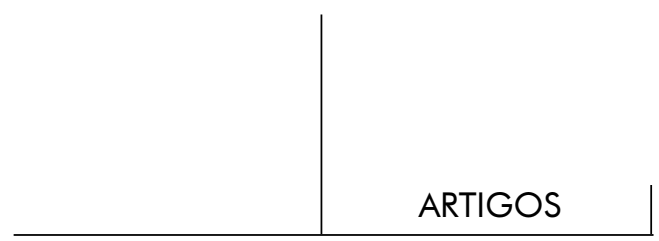

"Fetichismo" (1927) que essa distinção se tornou bastante clara, especialmente com a elaboração do conceito de desmentido (Verleugnung) e da afirmação do fetiche ser um substituto do pênis da mãe. Sendo assim, podemos compreender a perversão fetichista enunciada por Freud - a busca por um substituto para o pênis materno - como uma tentativa de abolir a diferença, o desejo do Outro. Lacan (1956-1957/1995, p. 154) indica que, nesse artigo freudiano de 1927, o fetiche é símbolo de alguma coisa, "mas que ficaremos sem dúvida alguma decepcionados com o que ele nos vai dizer", já que essa alguma coisa é, mais uma vez, o pênis. Todavia, acentua Lacan, não se trata do pênis real, é o pênis na medida em que a mulher não o tem. Melhor dizendo, não se trata em absoluto de um falo real na medida em que, como real, ele exista ou não, mas de um falo simbólico, unicamente na medida em que ele está ou não está ali, pois é assim que se instaura a diferença simbólica entre os sexos. Ele prossegue pontuando que é sempre o menino que é fetichista e nunca a menina.

Neste mesmo seminário, anteriormente à entrada na parte dedicada ao objeto fetiche - "um problema que materializa a questão do objeto de uma maneira particularmente aguda" (p. 153) -, Lacan monta o esquema do fetichismo (p. 84), através do qual é demonstrado que a mulher castrada, enquanto mãe, busca na relação com seu filho uma completude a partir do falo, objeto imaginário. Sem a interdição paterna, a criança, a partir de um deslocamento imaginário, fará a escolha fálica, identificando-se com a mãe. A responsabilidade por este funcionamento decai na falha da metáfora paterna.

Aproximando, então, da perversão, o falo - o significante sem significado que se suporta pelo gozo fálico - é o símbolo único, privilegiado e preciso do objeto fetiche. Poderíamos dizer que o fetichista busca uma saída imaginária através de um símbolo para negar a falta no Outro - castração simbólica - embora saiba perfeitamente que falta alguma coisa ao Outro. Vistos todos estes pontos, como inserimos a mulher na perversão fetichista? Ela não teria como negar a falta no Outro? Dizemos justamente "perversão fetichista" porque, se o fetichismo é o paradigma de toda perversão, ter-se-ia que adotar esta via para abordarmos a mulher na estrutura perversa.

Não podemos esquecer que o falo é um significante que não tem significado (Lacan, 1972-1973/2008, p. 87), ele não é uma fantasia, nem um objeto, tampouco o órgão que ele simboliza: o falo é um significante que só pode desempenhar seu papel enquanto velado, isto é, "como signo, ele mesmo, da latência com que é cunhado tudo o que é significável, a partir do momento em que é alçado (aufgehoben) à função de significante" (Lacan, 1958/1998, p. 699). Safouan (1977) alega que embora a imagem fálica pareça realizada no pênis, não haveria fantasia, desejo, nem projeção, se o pênis não fosse marcado por sua 
oposição ao impossível: impossível que seja falo. Pommier (1987) ainda sepulta de uma vez por todas qualquer confusão existente entre falo e pênis ao afirmar que reduzir a angústia de castração à descoberta da nudez do corpo feminino tem como mérito a clareza e a simplicidade. Mas uma "falta" (sic) só adquire significação sobre o fundo da presença potencial do símbolo fálico. Portanto, pode-se afirmar com todas as letras que o falo não é o pênis! Sabemos que não há sujeito sem linguagem, e ambos estão, por sua vez, intimamente interligados com o conceito de significante, portanto, acreditamos ser possível para uma mulher colocar como significante fálico qualquer outra coisa que não o pênis. Logo, ela poderia desmentir a castração do Outro - já que este processo não envolve o pênis - e simbolizar qualquer imagem como fálica, desde que guarde a significação de completude.

Lacan aproximou a mulher da perversão ao afirmar que não há nada mais característico na relação de objeto pré-edipiana do que o nascimento do objeto como fetiche, onde o esquema do fetichismo exemplifica bem isso. Neste caso, é importante frisar, a mãe está no lugar do sujeito masculino - adotando o quadro das fórmulas da sexuação de Lacan (1972-1973/2008) -, do sujeito desejante que busca o objeto do seu gozo (a criança). E se o lado mulher não fizer limite à mãe todo-fálica, essa mãe pode fazer do seu filho objeto da sua perversão. É de suma relevância apontar que quando a mulher não é reduzida ao seu sexo anatômico - como ocorre nos outros casos abordados pela própria psicanálise - parece possível colocá-la como perversa. Uma mulher, corpo biológico, identificada ao lado masculino, não poderia ser perversa? Uma mulher também pode se aproximar da perversão através do matema de Marie-Jean Sauret, Bernard Nominé e Pierre Bruno (1997 apud Costa, 2010), onde o filho é causa de desejo perverso para a mãe, assim como a mulher é causa de desejo perverso para o homem. Esse matema ilustra a versão do pai, a père-version, responsável por barrar a mãe (assegurando a não existência d'A mulher nem da mãe-toda) e vincular os três personagens edipianos:

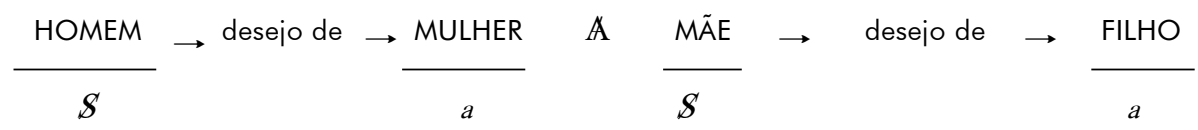

Pois bem, até agora tratou-se apenas da perversão fetichista. Dentre os "pares de opostos" freudianos sadismo-masoquismo e voyeur-exibicionista, o sadismo enquanto perversão foi colocado por Freud nos "Três ensaios sobre a teoria da sexualidade" (1905/2006) como uma satisfação exclusivamente condicionada pela sujeição e maus-tratos infligidos ao objeto sexual e, posteriormente, será 
acrescentado que "não é a dor em si que é fruída, mas a excitação sexual concomitante" (Freud, 1915/2007, p. 154). Ainda, tanto nos "Três ensaios..." quanto em "Pulsões e destinos da pulsão" (1915/2007), Freud fala do sadismo enquanto fenômeno primário, e o masoquismo como continuação do sadismo que se volta para a própria pessoa. Em "Além do princípio de prazer" (1920/2006) Freud já reformula sua teoria sobre o sadismo e o masoquismo, mas seu desenvolvimento mais completo será feito em "O problema econômico do masoquismo" (1924/2007).

No trabalho metapsicológico de Freud sobre as pulsões (1915/2007), a essência da pulsão é descrita de acordo com as suas principais características, como a sua fonte - o corpo - e a sua manifestação como força constante, sendo ela irremovível. Seu objetivo é sempre a satisfação, no entanto, ela nunca é alcançada, pois o sujeito está submetido às leis que particularizam o ser falante devido a sua passagem pela castração. Já o objeto é variável, pois não há o objeto primordial e sim objetos substitutivos, e é por intermédio deles que a pulsão alcança seu objetivo. Quando há uma fixação (Fixierung) da pulsão ao objeto, sua mobilidade fica comprometida, o que nos lembra o caso do perverso, cuja satisfação da pulsão ocorre de uma só maneira.

Alberti (2005) afirma que Freud já atentava para o fato que não há pulsão exceto no campo da fala e da linguagem. O perverso está submetido à exigência pulsional para não se deparar com o horror frente ao real traumático da castração, velando, assim, a castração do Outro, pois acredita que esta lhe seria mortal. O encontro com o real é tão insuportável para o perverso que é preferível desmenti-lo.

No entanto, para Lacan (1968-1969/2008, p. 246), o que importa nesses "pares de opostos" não está relacionado à atividade ou passividade da pulsão, mas à voz e ao olhar. Antes de ter a intenção de provocar qualquer pudor, susto ou medo na sua testemunha, o essencial para o exibicionista é fazer aparecer o olhar no campo do Outro. Ele zela pelo gozo do Outro. "É no nível desse campo, campo do Outro como desertado pelo gozo, que o ato exibicionista se coloca, para ali fazer surgir o olhar. É nisso que vemos que ele não é simétrico ao que acontece com o voyeur" (p. 246). Para o voyeur, a importância paira em interrogar no Outro o que não se pode ver. Enquanto o olhar está relacionado ao desejo ao Outro - é o que se espera do Outro -, a voz se refere ao desejo do Outro, ao que se recebe do Outro. É a partir da compreensão do que acontece com a função do objeto $a$ efetivada pela voz como suporte da articulação significante que é possível conceber a função do supereu. Se o sádico tenta completar o Outro roubando-lhe a sua fala e impondo-lhe sua voz, o masoquista faz da voz do Outro "aquilo a que dará a garantia de responder como um cão" (p. 249); há um gozo na reposição da função da voz no Outro. 
Fonte de inspiração para o termo sadismo, Sade foi um grande crítico do Iluminismo, tendo trazido à luz a violência do erotismo que a cultura sempre tentou ocultar. Para ele, se a natureza era o verdadeiro fundamento, e não Deus, não cabia aos homens reprimirem seu próprio lado destrutivo natural; a civilização e suas leis morais que desumanizariam o homem. Com que direito deve-se reprimir aquele que só sente prazer infligindo dor aos outros, se tal prazer é ditado pela própria natureza, a qual, na verdade, está acima dos homens?

Poder-se-ia dizer que, para Sade, dar vazão às pulsões seria a sua ética, e o gozo seria a sua finalidade. Ética esta que estaria acima das meras convenções humanas de bem e mal, certo e errado. Ele justifica ponto por ponto a demolição dos imperativos fundamentais da lei moral, e preconiza o incesto, o adultério, o roubo, e assim por diante. Em "Kant com Sade" (1966/1998) aprendemos que, em Kant, a lei impera, mas não é sem gozo, enquanto que para Sade é o gozo que o rege, mas não sem lei; é um tratado da moral às avessas. O perverso está no campo da Lei (castração do Outro), este responsável por fundar o desejo. No entanto, o desejo, tanto quanto a Lei, forma uma barreira em relação ao gozo, e este último, por sua vez, é essencial ao perverso para tapar o furo do Outro, a castração, que ele insiste em desmentir.

Por isso, Lacan (1966/1998, p. 786) imprime o seguinte esquema para demonstrar a fantasia sadiana, relacionando o perverso com a sua vítima:

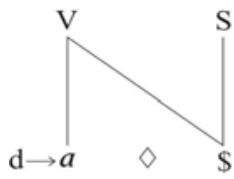

Entendemos que, movido por seu desejo (d), o perverso se coloca na posição de objeto $a$ - gozo - onde se serve de instrumento de uma vontade de gozo absoluto $(\mathrm{V})$, dividindo o seu parceiro entre a submissão à voz imperativa e a revolta contra os maus-tratos infligidos ( $\$$ ), pois é preciso que a "vítima" se coloque nesse lugar apontado pelo perverso, mas não consinta com ele. Como nos auxilia André (1995), a manobra de Sade visa produzir um sujeito mítico, nunca atingido, um puro sujeito do prazer (S). O sádico, por exemplo, põe seu parceiro no lugar do sujeito - aquele que se divide, que não consente com o perverso - para o gozo do Outro, pois o sádico obriga a sua vítima a descobrir em si um gozo que ela própria desconhece. Alberti (2005, p. 35) complementa afirmando 


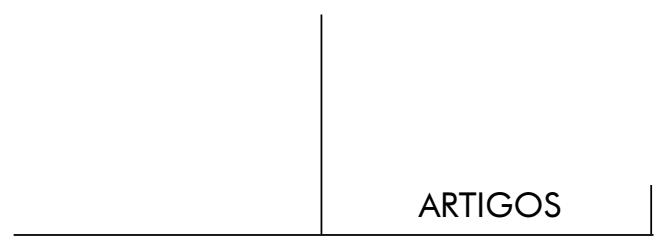

que quando se desidentifica do lugar do sujeito, "é também a castração que se desmente, pois não há sujeito que não sofra o efeito da castração". Como Freud nos ensinou nos seus "Três ensaios..." (1905/2006), o sadismo e o masoquismo são vertentes de uma mesma perversão, cujas formas ativa e passiva têm proporções variáveis no mesmo indivíduo: um sádico é também sempre um masoquista, embora um jamais busque parceria com o outro. Além do plano das perversões, a atividade e a passividade características deste par de opostos são constitutivas da vida sexual em geral.

A partir do matema da fantasia perversa $(a \diamond \$)$ explicitado por Lacan, por que uma mulher não poderia ocupar o lugar de objeto $a$ ? Será mesmo que, frente à castração, ela só tem a saída neurótica ou psicótica?

Serge André (1995) revela o percurso de duas mulheres envolvidas amorosamente que o procuraram a fim de fazer análise. Ele acredita que uma delas seja perversa, enquanto a outra, histérica. Seu diagnóstico gerou (e ainda gera) muitas controvérsias, pois entende-se que em ambos os casos se trata de neurose histérica. Deixando momentaneamente de lado a avaliação do autor, ressaltamos a importância de um psicanalista renomado, como Serge André, acreditar na possibilidade (e escrever sobre isso) de haver mulheres perversas, visto a descrença quase total dos profissionais sobre essa questão. Esta descrença por si só na mulher perversa já não é um obstáculo suficientemente grande para não reconhecê-la?

\section{Para concluir}

Assim, a inquietação que motivou este artigo permanece. Destacamos o quanto, na psicanálise, há posições antagônicas quanto a existir mulheres na estrutura perversa, uma vez que é afirmado que elas não têm como desmentir (Verleugnung) a castração. Perguntamos se a percepção da ausência do pênis seria suficiente e exclusiva para que seja vetada às mulheres a estrutura perversa, sugerindo que qualquer outra coisa - seja um órgão, objeto etc. - poderia atrair a função fálica.

Supondo uma mulher perversa, diríamos que ela acredita ter o falo. Ainda quando ela comete um ato ilícito apoiando-se no parceiro, podemos supor que ela acredita que desta forma desmente o horror da castração, do limite, da incompletude, do encontro com o real traumático do sexo.

A sexualidade é um dos grandes mistérios, tal qual a morte. Ela é traumática por tratar do encontro com o real do sexo. "O real é o que há por trás da fantasia, é o encontro com o faltoso, com o que pode faltar e corresponde ao 
traumatismo, guardando uma relação íntima com o processo primário" (Manso de Barros \& Tarré, 2009, p. 121-122). Cada um tem a sua particular maneira de lidar com o real, podendo haver tantos sexos quanto sujeitos no mundo.

\section{Referências}

Alberti, S. (2005 setembro). A perversão, o desejo e a pulsão. Mal-estar e subjetividade. v. 5, n. 2, pp. 341-360. Recuperado em 15 de junho de 2009 do http:// www.unifor.br/notitia/file/980.pdf.

André, S. (1995). A impostura perversa. Rio de Janeiro: Jorge Zahar.

Askofaré, S. (2006). La perversion généralisée. In S. Askofaré, Les réalités sexuelles et l'inconscient (pp. 219-226). Paris: EPCFCL.

Costa, T. (2010). Édipo. Rio de Janeiro: Jorge Zahar.

Ferraz, F. C. (2004). Perversão. São Paulo: Casa do Psicólogo.

Freud, S. (2006). Três ensaios sobre a teoria da sexualidade. In S. Freud, Edição Standard Brasileira das Obras Psicológicas Completas de Sigmund Freud (pp. 119-231). Rio de Janeiro: Imago. (Trabalho original publicado em 1905).

Freud, S. (1992). Sobre a gênese do fetichismo. Revista Internacional da história da psicanálise. Rio de Janeiro, n. 2, pp. 371-387. (Trabalho original publicado em 1909).

Freud, S. (2004). Pulsões e destinos da pulsão. In S. Freud, Escritos sobre a psicologia do inconsciente - Obras psicológicas de Sigmund Freud (pp. 133-174). Rio de Janeiro: Imago, v. 1. (Trabalho original publicado em 1915).

Freud, S. (2006). Além do princípio de prazer. In S. Freud, Escritos sobre a psicologia do inconsciente: obras psicológicas de Sigmund Freud (pp. 123-198). Rio de Janeiro: Imago, v. 2. (Trabalho original publicado em 1920).

Freud, S. (2006). Psicologia de grupo e análise do ego. In S. Freud, Edição Standard Brasileira das Obras Psicológicas Completas de Sigmund Freud (pp. 79-159). Rio de Janeiro: Imago, v. 18. (Trabalho original publicado em 1921).

Freud, S. (2007). O problema econômico do masoquismo. In S. Freud, Escritos sobre a psicologia do inconsciente: obras psicológicas de Sigmund Freud (pp. 103-124). Rio de Janeiro: Imago, v. 3. (Trabalho original publicado em 1924).

Freud, S. (2007). Fetichismo. In S. Freud, Escritos sobre a psicologia do inconsciente: obras psicológicas de Sigmund Freud (pp. 125-134). Rio de Janeiro: Imago, v. 3. (Trabalho original publicado em 1927).

Freud, S. (2006). Sexualidade feminina. In S. Freud, Edição Standard Brasileira das 


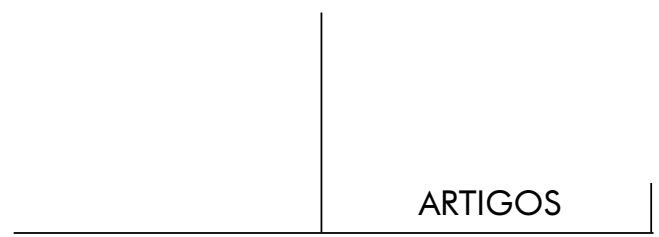

Obras Psicológicas Completas de Sigmund Freud (pp. 231-251). Rio de Janeiro: Imago, 2006, v. 21. (Trabalho original publicado em 1931).

Freud, S. (2007). A cisão do Eu no processo de defesa. In S. Freud, Escritos sobre a psicologia do inconsciente: obras psicológicas de Sigmund Freud (pp. 171-180). Rio de Janeiro: Imago, v. 3. (Trabalho original publicado em 1940[1938]).

Lacan, J. (1995). O seminário. Livro 4. A relação de objeto. [Rio de Janeiro: Jorge Zahar, 1995. (Trabalho original publicado em 1956-1957).

Lacan, J. (1998). A significação do falo. In J. Lacan, Escritos (pp. 692-703). Rio de Janeiro: Jorge Zahar. (Trabalho original publicado em 1958).

Lacan, J. (1998). Kant com Sade. In J. Lacan, Escritos (pp. 776-803). Rio de Janeiro: Jorge Zahar. (Trabalho original publicado em 1966).

Lacan, J. (2008). O seminário. Livro 16. De um Outro ao outro. Rio de Janeiro: Jorge Zahar. (Trabalho original publicado em 1968-1969).

Lacan, J. (2008). O seminário. Livro 20. Mais, ainda. Rio de Janeiro: Jorge Zahar. (Trabalho original publicado em 1972-1973).

Manso de Barros, R. M. \& Tarré, G. F. (2009). O que fazer com o real do trauma. In Lima M. Antonio C. J. L. \& Lima. M. M. de (Orgs.). Saber fazer com o real (pp. 119-129). Rio de Janeiro: Cia. de Freud.

Millot, C. (1992). Extrasexo: ensaio sobre o transexualismo, São Paulo: Escuta.

Pommier, G. (1987). A exceção feminina: os impasses do gozo. Rio de Janeiro: Jorge Zahar.

Sade, Marquês de (2008). A filosofia na alcova: os preceptores imorais [1795]. São Paulo: Iluminuras. Tradução, posfácio e notas de Augusto Contador Borges. (Trabalho original publicado em 1795).

Safouan, M. (1977). A sexualidade feminina na doutrina freudiana. Rio de Janeiro: Zahar.

Stoller, R. (1968). Sex and gender. New York: Science House.

Valas, P. (1990). Freud e a perversão. Rio de Janeiro: Jorge Zahar.

\section{Resumos}

\section{(A perverse woman?)}

This article consists of a discussion on the existence of structurally perverse women, in terms of psychoanalytic theory as developed by Freud and Lacan. At the beginning 
it was difficult to distinguish perversion, as a specific structure, from psychosis and neurosis, due to the perverse-polymorphic characteristics of human sexuality. A major issue here is if a woman can have a perverse structure, or if perversion is found only in men.

Keywords: Perversion, psychoanalysis, woman, feminine

\section{(Femmes perverses?)}

Cet article propose de discuter l'existence de femmes structurellement perverses à partir de la théorie psychanalytique, soit à partir des contributions de Freud et de Lacan. Une des difficultés initiales de l'étude de la perversion est de l'isoler comme structure spécifique et de la distinguer de la psychose et de la névrose, dû à la manifestation polymorphe-perverse de la sexualité humaine. Néanmoins, une des questions les plus discutées examine si la structure perverse inclut les femmes ou si elle se limite uniquement aux hommes.

Mots clés: Perversion, psychanalyse, femme, féminin

\section{(¿Mujer perversa?)}

Este artículo se propone a discutir la existencia de mujeres estructuralmente perversas a partir de las contribuciones psicoanalíticas de Freud y de Lacan. Primeramente, al estudiar la perversión, existe la dificultad de aislarla como una estructura específica que se distingue de la psicosis y de la neurosis debido a la manifestación polimorfaperversa de la sexualidad humana. Sin embargo, una de las cuestiones más discutidas es si hay mujer en la estructura perversa, o si se restringe solamente a los hombres.

Palabras llave: Perversión, psicoanálisis, mujer, femenino

(Perverse Frau?)

Ziel dieses Beitrages ist die Diskussion der Existenz von strukturell perversen Frauen, ausgehend von der psychoanalytischen Theorie anhand der Beiträge von Freud und Lacan. Zu Beginn der Studie der Perversion, steht man vor der Schwierigkeit, sie als eine spezifische Struktur zu isolieren und von der Psychose und der Neurose zu unterscheiden, wegen der pervers-polymorphen Äußerung der menschlichen Sexualität. Doch eine der meistdiskutierten Fragen ist ob die perverse Struktur auch Frauen einbezieht oder ausschließlich Männer betrifft.

Schlüsselwörter: Perversion, Psychoanalyse, Frau, weiblich

Citação/Citation: Manso de Barros, R. M. \& Mendonça, L. G. S. F. (2013 junho). Mulher perversa? Revista Latinoamericana de Psicopatologia Fundamental, 16(2), 218-231.

Editor do artigo/Editor: Prof. Dr. Manoel Tosta Berlinck 


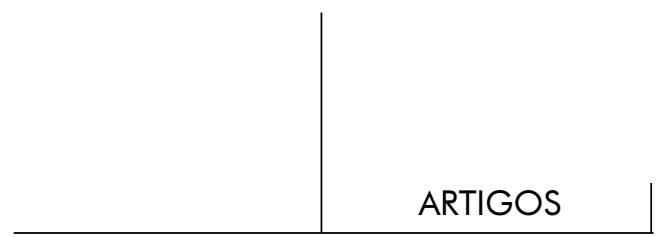

Recebido/Received: 10.4.2012/4.10.2012 Aceito/Accepted: 19.8.2012 / 8.19.2012

Copyright: () 2009 Associação Universitária de Pesquisa em Psicopatologia Fundamental/ University Association for Research in Fundamental Psychopathology. Este é um artigo de livre acesso, que permite uso irrestrito, distribuição e reprodução em qualquer meio, desde que o autor e a fonte sejam citados / This is an open-access article, which permits unrestricted use, distribution, and reproduction in any medium, provided the original author and source are credited.

Financiamento/Funding: As autoras declaram ter sido financiadas ou apoiadas pela Capes Coordenação de Aperfeiçoamento de Pessoal de Nivel Superior (Brasília, DF, Br) / This research is funded by Capes - Coordenação de Aperfeiçoamento de Pessoal de Nivel Superior (Brasília, DF, Br).

Conflito de interesses/Conflict of interest: As autoras declaram que não há conflito de interesses / The authors declare that has no conflict of interest.

\section{Rita Maria Manso de Barros}

Psicanalista; Doutora em Teoria Psicanalítica pela Universidade Federal do Rio de Janeiro UFRJ (Rio de Janeiro, RJ, Br.); Diretora do Instituto de Psicologia e Professora do Programa de Pós-graduação em Psicanálise da Universidade do Estado do Rio de Janeiro - UERJ (Rio de Janeiro, RJ); Professora Associada do Instituto de Psicologia da Universidade do Estado do Rio de Janeiro - UERJ (Rio de Janeiro, RJ) e do Departamento de Fundamentos da Educação da Universidade Federal do Estado do Rio de Janeiro - UNIRIO (Rio de Janeiro, RJ, Br.).

Rua Maestro Francisco Braga, 170/202 - Peixoto, Copacabana

22041-070 Rio de Janeiro, RJ, Br.

e-mail: ritamanso@globo.com

\section{Ligia Gama e Silva Furtado de Mendonça}

Doutoranda e Mestre em Pesquisa e Clínica em Psicanálise e Especialista em Psicanálise e Saúde Mental pela Universidade Federal do Rio de Janeiro - UERJ (Rio de Janeiro, RJ, Br.)

Av. André Grabois, 510 - Recreio dos Bandeirantes

22790-869 Rio de Janeiro, RJ, Br.

e-mail: ligia.mendonca@gmail.com 